\title{
Análise da Dinâmica Populacional por Nível de Instrução no Brasil
}

\author{
Analysis of Population Dynamics by Education Level in Brazil
}

Gabriela Henrique Zangiski e Alexandre Alves Porsse ${ }^{* *}$

\begin{abstract}
Resumo: Este estudo visa analisar os efeitos de migração regional a partir da avaliação das mudanças ocorridas na estrutura da população segundo o nível de instrução. A hipótese é de que os grupos populacionais mais escolarizados são mais propensos a migrar e que os diferenciais regionais dos grupos populacionais devem refletir os efeitos de migração. A metodologia empregada baseia-se em duas abordagens: análise exploratória de dados espaciais e análise shift-share, sendo que a primeira permite identificar regimes espaciais nos componentes da análise shift-share e a segunda decompõe os efeitos diferenciais regionais. Foram encontrados padrões significativos de dependência espacial para todos os níveis de instrução. As regiões Nordeste e Norte destacaram-se pelo aumento da participação de indivíduos de menor instrução, enquanto o Centro-Oeste mostrou-se atrativo para os mais escolarizados, indicando que a estrutura produtiva desta região tem incrementado o uso de trabalho qualificado.
\end{abstract}

Palavras-chave: Economia regional. Dinâmica populacional. Nível de instrução

\begin{abstract}
This study aims to analyze the effects of regional migration from the evaluation of the changes that occurred in the population structure according to the level of education. The hypothesis is that the most educated population groups are more likely to migrate and that regional differentials of population groups should reflect the effects of migration. The methodology used is based on two approaches: exploratory analysis of spatial data and shift-share analysis, the former allowing for the identification of spatial regimes in the components of the shift-share analysis and the second decomposing the regional differential effects. Significant patterns of spatial dependence were found for all levels of education. The Northeast and North regions stood out by increasing the participation of individuals with lower education, while the Center-West proved attractive to the more educated, indicating that the productive structure of this region has increased the use of skilled labor.
\end{abstract}

Keywords: Regional Economics. Population growth. Level of education

JEL: R23. J61

\footnotetext{
* Submissão: 28/02/2020 | Aprovação: 28/09/2020 | DOI: 10.5380/re.v42i79.71982

** Respectivamente: (1) Doutoranda em Economia pela EPGE/ FGV | ORCID: 0000-0002-1800-8196 | Email: gabriela.zangiski@gmail.com | (2) Professor Associado do Departamento de Economia da UFPR e Pesquisador Produtividade em Pesquisa do CNPq | ORCID: 0000-0002-2858-9043 | E-mail: porsse@gmail.com | Os autores agradecem ao suporte do CNPq para o desenvolvimento desta pesquisa.
}

Esta publicação está licenciada sob os termos de

Creative Commons Atribuição-Não Comercial 4.0 Internacional 


\section{Introdução}

A migração constitui um fenômeno complexo que exerce grande impacto no Brasil e pode estar fortemente relacionada com a escolaridade dos indivíduos. Entender as características da estrutura populacional é fundamental para compreender a economia brasileira não apenas como um todo, mas principalmente a nível regional.

Um dos componentes mais importantes da análise econômica sobre a migração é, portanto, o nível de instrução dos indivíduos, uma vez que esta variável tem fundamental influência na escolha de permanecer no local de origem ou migrar, e, caso ocorra a decisão de migrar, para onde. Além disso, alterações no nível de instrução da população em uma região impactam diretamente sua economia, principalmente via alteração do salário de equilíbrio no mercado de trabalho e da produtividade nos segmentos da economia.

Um estudo neste contexto já foi feito por Sabbadini e Azzoni (2006), comparando os dados dos censos de 1991 e 2000. Contudo, ainda se faz necessária uma análise de dados para o Brasil, com relação à migração por nível de instrução para os dados de 2000 e 2010. Desta forma, o objetivo deste estudo é realizar uma análise da estrutura populacional no Brasil, segundo o nível de instrução, comparando os dados dos censos de 2000 e 2010 a respeito da população regional para cada grupo de anos de estudo, esperando encontrar evidências de migração relacionada ao nível de instrução. Cabe ressaltar que a investigação acerca das motivações e dos impactos desses fluxos migratórios foge do escopo desta pesquisa.

Assim, após esta introdução, este estudo se divide em outras quatro partes. A seguir, é feita uma revisão de literatura acerca do tema, apontando os principais conceitos, o embasamento teórico econômico que relaciona nível de instrução e migração, e estudos relevantes, além de uma contextualização da migração populacional no Brasil. A descrição da metodologia utilizada para a análise de dados, bem como as variáveis e os dados empregados nesta pesquisa se encontram na terceira seção. Em seguida, a quarta parte deste estudo apresenta os resultados obtidos a partir da metodologia empregada, indicando as observações que podem ser feitas acerca dos mesmos, suas implicações econômicas e principais aspectos. Por fim, serão assinaladas as considerações finais sobre o estudo. 


\section{Revisão de literatura}

\subsection{Teorias da Migração Populacional}

A migração populacional é definida como a saída de um indivíduo ou um grupo de indivíduos de determinado espaço geográfico, com a finalidade de residir em outro, seja de forma temporária ou permanente. No Brasil, é considerado migrante o indivíduo que passa a residir em outro município que não o de sua origem $^{1}$. Além disso, conceitua-se emigração a saída de determinado local e a imigração como a destinação para outro lugar (Golgher, 2004).

O principal motivo para migração é a busca por melhores condições de vida. Economicamente, isso se traduz na busca por salários maiores, chamada por Bodvarsson \& Van den Berg (2013) de "migração puramente econômica". No entanto, cabe ressaltar que outros fatores também impactam esta decisão (Bodvarsson; Van Den Berg, 2013). Sjaastad (1962) é pioneiro em considerar estes outros fatores em seus modelos e vê a migração também como um investimento em capital humano. Como continuidade, a Teoria do Capital Humano vê a migração como uma decisão racional, tomada considerando-se todos os hábitos e atividades dos indivíduos (Becker, 1993).

As principais teorias que tratam da migração do ponto de vista econômico possuem base nos modelos de oferta e demanda de trabalho. Estas teorias são apresentadas de forma mais detalhada em Bodvarsson \& Van den Berg (2013). A tendência, portanto, é que os trabalhadores de lugares com salários menores migrem para lugares com salários maiores, em busca de um aumento em sua remuneração e qualidade de vida. Assim, este fluxo ocorrerá até que os salários de equilíbrio dos dois mercados de trabalho se igualem.

A partir desse mecanismo, Borjas (1995) conclui que a migração é economicamente benéfica, principalmente se as especializações - ou o nível de instrução - dos nativos e dos migrantes são diversificadas e apresentam uma relação de complementariedade. Isto é: lugares onde a oferta agregada de trabalho é composta majoritariamente por indivíduos com baixo nível de instrução serão mais beneficiados ao receber migrantes com maiores níveis de instrução, enquanto áreas com maior grau de escolaridade se beneficiarão mais ao receber migrantes com menor escolaridade.

\footnotetext{
${ }^{1}$ Há ainda a migração pendular, em que o indivíduo se desloca diariamente entre cidades da região metropolitana por residir em um município e trabalhar ou estudar em outro.
} 
Borjas (1991) elabora também um modelo de migração que considera o nível de instrução como variável de influência sobre a renda média (ganhos). Observando este modelo, é possível apontar uma tendência de migração maior por parte dos indivíduos com maiores níveis de instrução para lugares com maiores disparidades de renda.

A partir destes modelos, algumas características dos migrantes são destacadas nas observações de diversos estudos (Ferreira; Matos, 2006; Sabbadini; Azzoni, 2006; Hakkert; Martine, 2010; Golgher, 2004), constituindo a chamada "seletividade dos migrantes". Segundo Golgher (2004), os migrantes são, em suma, jovens com certo grau de instrução, em busca de melhores salários. A tendência de migração de indivíduos com maior nível de instrução caracteriza a denominada "fuga de cérebros".

Desta forma, fica evidenciado pela teoria econômica que há incentivos para migração que estão relacionados ao nível de escolaridade dos indivíduos. Portanto, espera-se observar mudanças na composição populacional brasileira de acordo com o nível de instrução dos indivíduos ao longo do tempo. No entanto, os efeitos esperados podem ficar mais claros diante de uma análise histórica da migração no Brasil, o que será feito na próxima seção.

\subsection{Migração populacional no Brasil}

O Brasil é historicamente repleto de movimentos de migração populacional, desde a vinda de colonizadores e escravos no início da história do país, até a formação dos fluxos migratórios internos mais recentes. Movimentos como a ocupação e a exploração do interior pelos bandeirantes, a corrida do ouro para as regiões mineiras, a transferência de escravos da região Norte para o Sudeste para o plantio do café, a saída de nordestinos para o Norte em ocasião do ciclo da borracha, entre outros, foram fundamentais na formação do espaço econômico, social e geográfico do Brasil, bem como para o entendimento dos processos históricos pelos quais estes movimentos foram ocasionados (Furtado, 1959; Sabbadini; Azzoni, 2006).

De maneira geral, é possível apontar que esses movimentos foram motivados por fatores econômicos: os indivíduos que compuseram estes fluxos se deslocaram (ou foram deslocados, no caso dos escravos) motivados por expectativas em 
aumentar seu rendimento. Cabe notar que as motivações podem evidenciar algumas das características dos migrantes, dentre as quais encontra-se a escolaridade.

Há estudos a respeito das migrações no Brasil com relação ao nível de instrução para dados a partir dos anos 1950. Campino (1973), analisando dados disponíveis para o período de 1950 a 1970, destaca que os fluxos migratórios de indivíduos pouco qualificados se dão na direção de regiões mais desenvolvidas, como é o caso do fluxo Nordeste-São Paulo. Da mesma forma, os fluxos de indivíduos com maiores níveis de instrução se dão na direção das áreas menos desenvolvidas, beneficiando estas regiões. Assim, o autor levanta a hipótese de que a redução na disparidade de renda entre os estados brasileiros tenha se dado, entre outros fatores, pelo aumento na demanda por mão de obra qualificada nos estados menos desenvolvidos.

Segundo Hakkert e Martine (2010), em uma análise dos dados do censo de 1970, os migrantes tendiam sistematicamente a ter baixa renda e escolaridade, origem rural e má colocação no mercado de trabalho do local de destino. Em contraste, analisando dados dos anos de 1995 e 2000, Golgher (2006), traça um perfil mais atualizado dos migrantes no Brasil: os migrantes são, em geral, mais escolarizados, urbanizados e recebem renda média maior do que aqueles que optaram por não migrar. O autor também conclui que "pessoas com maior escolaridade e renda aparecem em maiores proporções entre os migrantes" (Golgher, 2006, p. 5).

Analisando os dados para os períodos 1986-1991 e 1991-2000, Oliveira e Simões (2004) concluem que as migrações para São Paulo perdem volume, e o estado, que era principal destino dos migrantes brasileiros, passa a ser destaque como ponto de origem para a migração no país. Já as regiões Sul e Nordeste passam a receber mais migrantes do que nos períodos anteriores. A região Sul, devido principalmente ao seu desenvolvimento, e a região Nordeste, devido à migração de retorno da população que anteriormente havia se deslocado para regiões mais desenvolvidas.

Os autores apontam que indivíduos com menor nível de instrução representam uma parcela reduzida dos migrantes. Além disso:

No que se refere às características dos migrantes, foi possível observar que os indivíduos de mais baixa qualificação deslocaram-se de forma mais intensa pelas regiões Norte e Nordeste do País. Ao contrário, nas regiões Sudeste e Sul houve uma maior circulação de pessoas com 
maior qualificação. Esses resultados refletem a distribuição das atividades produtivas no território brasileiro, onde os espaços mais dinâmicos, que se encontram nas regiões Sudeste e Sul experimentaram uma movimentação mais intensa deste contingente populacional (Oliveira; Simões, 2004, p. 16).

Também com relação ao período de 1991-2000, Sabbadini e Azzoni (2006) apontam a existência da fuga de cérebros no Brasil, tendo como origem as regiões que oferecem mais programas de pós-graduação - as mesmas regiões citadas por Oliveira e Simões (2004) como espaços mais dinâmicos - para as regiões que possuem menos programas de pós-graduação, ou até não possuem - as áreas ditas por Oliveira e Simões (2004) como locais de maior circulação de indivíduos de baixa qualificação.

Da mesma maneira, Sabbadini e Azzoni (2006) apontam um saldo migratório negativo na região Sudeste e um saldo migratório positivo para as regiões Sul e Nordeste, revertendo os valores absolutos obtidos em estudos para períodos anteriores. Os autores também notam a presença de um saldo migratório negativo para as regiões Centro-Oeste e Norte.

Já Rigotti (2006) aponta que, para o período de 1995-2000, as principais cidades de origem dos migrantes com alto nível de instrução eram regiões metropolitanas ou capitais de unidades de federação. Os principais destinos desta população eram centros de aglomerações urbanas, com destaque para a tendência do surgimento de novas economias de aglomeração. $\mathrm{O}$ autor também constata que, quanto aos fluxos migratórios no Sul, as cidades do interior são receptoras de indivíduos com maior grau de instrução, enquanto as cidades metropolitanas recebem mão de obra com menos qualificação.

Por fim, a partir da análise de dados dos períodos de 1995-2000 e 1999-2004, Hakkert e Martine (2010) assinalam uma redução significativa no volume de migração inter-regional, além da inversão do sentido do fluxo NordesteSudeste, redução da emigração do Sul e um pequeno aumento da migração do Centro-Oeste para o Nordeste.

Em síntese, os estudos das migrações no Brasil demonstram que os migrantes com maiores níveis de instrução tendem a sair das áreas mais desenvolvidas do país em direção às áreas em desenvolvimento, que por sua vez, são apontadas por Rigotti (2006) e Hakkert e Matrine (2010) como novas áreas de aglomeração urbana, que surgem devido às novas dinâmicas econômicas e a especialização de algumas 
regiões no país. Da forma complementar, os estudos apontam que os migrantes com menores graus de escolaridade tendem a sair das áreas menos desenvolvidas do Brasil, em direção às maiores aglomerações urbanas.

Além disso, Hakkert e Martine (2010) e Rigotti (2006) afirmam que, em geral, os migrantes podem ser ditos, comparativamente aos não migrantes, como pessoas com maiores níveis de instrução e renda, sendo considerada esta última consequência tanto da migração quanto da escolaridade dos indivíduos.

Estas tendências da migração de pessoas qualificadas para áreas em desenvolvimento e de indivíduos com menores níveis de instrução para regiões mais desenvolvidas corroboram a teoria de Borjas (1995) a respeito da complementariedade de capital humano. Uma vez que áreas desenvolvidas tendem a possuir maior concentração de pessoal qualificado, estes locais atraem indivíduos com menor escolaridade, a fim de aumentar a produtividade. Da mesma maneira, regiões em desenvolvimento tendem a apresentar maior abundância de mão de obra pouco qualificada, de forma que geralmente são mais atrativas para indivíduos com maiores níveis de escolaridade, devido à presença maiores retornos à educação.

De maneira geral, migrantes direcionaram-se e continuam se direcionando nos sentidos dos investimentos econômicos, como é o caso do fluxo migratório em direção à Brasília que ocorreu período de construção da capital. Entretanto, "a relação entre estímulo e imigração não é perfeita nem mediata" (Hakkert; Martine, 2010, p. 348), mas tende a ser defasada devido ao fluxo imperfeito de informações. Os autores citam que, por exemplo, apesar de o processo de desconcentração industrial a partir da Região Metropolitana de São Paulo ter tido início na década de 1970, os impactos sobre a distribuição espacial da população só puderam ser percebidos a partir do censo demográfico de 1991.

Freguglia e Procópio (2013) observam que a escolaridade e os salários estão positivamente relacionados, corroborando a Teoria do Capital Humano. Contudo, Gama e Machado (2014) apontam uma queda dos diferenciais retornos à educação no Brasil, devido ao aumento no nível educacional da população brasileira, conforme demonstrado por Hakkert e Martine (2010). Essa informação é reiterada por Sabbadini e Azzoni (2006, p. 10), com base nos dados dos censos de 1991 e 2010: “(...) o número de pós-graduados no Brasil cresceu a uma taxa muito superior à da população brasileira $(8 \%$ a.a $)(\ldots)$ ”. Uma vez tendo aumentado a 
oferta de mão de obra qualificada no país em relação a demanda, são reduzidos os retornos à qualificação.

Outro tema bastante explorado pelos autores a respeito da migração populacional no Brasil é a migração de retorno, que tem sido um fenômeno de destaque no Brasil nas últimas décadas. Em geral, a população que retorna ao seu local de origem possui um menor nível de instrução do que os migrantes que não retornam, no entanto, recebem, em média, mais do que os indivíduos que permaneceram em sua região de origem (Brzozowski, 2012; Rigotti, 2006; Ramalho; Queiroz, 2011). Além disso, Hakkert e Martine (2010, p. 15) sugerem que esta população não retorna com a finalidade de se aposentar.

Esses indivíduos, em sua maioria, saem de regiões metropolitanas com destino a cidades menores e interioranas no processo de retorno. Esses fluxos se destacam com relação à região Nordeste, de forma que é possível supor que constituam explicação para o aumento dos fluxos recentes de migração com destino a esta região. Entretanto, recentemente, para região Sul também pode ser apontado um menor, porém significativo fluxo de migração de retorno (Brzozowski, 2012; Rigotti, 2006; Ramalho; Queiroz, 2011). Assim, Sabbadini e Azzoni (2006) sugerem que, para as regiões que recebem fluxos de migração de retorno, há um "ganho de cérebros".

Portanto, é possível observar que os fluxos migratórios identificados no Brasil, em todos os períodos analisados pelos autores citados, seguem as teorias econômicas anteriormente apresentadas. São respeitadas as condições de atração pela demanda por trabalho mais ou menos especializado, conforme a situação da região do país, assim como os impactos das alterações causadas na oferta de trabalho pelos fluxos migratórios. Assim, conclui-se que, de forma geral, os indivíduos se comportam de acordo com o esperado pela análise econômica.

Em suma, a partir dos autores acima citados, as análises mais recentes do tema para o Brasil apontam a migração para regiões em desenvolvimento em busca de melhores salários. Os migrantes, em geral, possuem certo nível de instrução e partem de regiões menos desenvolvidas e dos grandes aglomerados urbanos que apresentam deseconomias de escala. Assim, espera-se observar nos resultados desta pesquisa fenômenos que possam caracterizar a fuga de cérebros, a migração de retorno e a busca por maiores salários, em resposta ao grau de escolaridade do indivíduo. 


\section{Metodologia e base de dados}

\subsection{Descrição das variáveis}

Para atingir os objetivos dessa pesquisa, foi utilizada apenas a variável "anos de estudo", devido à sua disponibilidade e compatibilidade entre os censos de 2000 e 2010. Ela informa o número de residentes em determinada microrregião pertencentes a cada categoria de escolaridade. Esta variável encontra-se subdividida em quatro categorias, além do total:

- 0 - sem instrução ou menos de 3 anos de estudo (ensino primário incompleto)

- 1 - de 4 a 7 anos de estudo (ensino fundamental/ ginásio/ $1^{\circ}$. Grau/ médio primeiro ciclo incompleto)

- 2 - de 8 a 10 anos de estudo (ensino médio/ $2^{\circ}$. Grau/ médio segundo ciclo incompleto)

- 3 - de 11 a 14 anos de estudo (ensino médio/ $2^{\circ}$. Grau/ médio segundo ciclo completo ou superior incompleto)

- 4 - 15 ou mais anos de estudo (ensino superior completo, mestrado, doutorado)

Foram utilizados os dados a respeito dos anos de estudo disponíveis para cada categoria, segundo a divisão por microrregiões. Os anos aos quais este estudo se refere, portanto, são os anos de 2000 e 2010, referentes aos censos realizados pelo IBGE (Instituto Brasileiro de Geografia e Estatística). Esta escolha se deve ao fato de que o Censo feito pelo IBGE apresenta um número de observações muito maior que os de outras pesquisas. Além disso, os dados dos Censos de 2000 e 2010 são compatibilizáveis entre si e estão divididos em categorias que fornecem a informação necessária em relação à escolaridade dos indivíduos.

Desta maneira, foram utilizados os dados sobre os anos de estudo da população em cada microrregião de maneira que, analisando-se a diferença entre o número de indivíduos em cada categoria entre os anos de 2000 e 2010 através do shift-share, é possível obter evidências de migração. O efeito diferencial calculado via shift-share, como será exposto adiante, revela variações no número de indivíduos pertencentes a cada categoria de anos de estudo que não são decorrentes dos fatores que levariam à variação teórica do número de indivíduos nesta categoria, como crescimento populacional e crescimento da escolaridade da população na região. Desta maneira, eliminando estes fatores responsáveis pela 
variação teórica, obtemos a variação diferencial, que mostra os indícios de migração de indivíduos de cada categoria.

Após a aplicação da metodologia shift-share, os resultados em valores absolutos foram convertidos em taxas percentuais em relação ao nível populacional total de cada microrregião no período inicial (2000). A vantagem deste procedimento é obter estimativas dos componentes da análise relativizados pelo tamanho populacional das microrregiões.

\subsection{Análise exploratória de dados espaciais}

A análise exploratória de dados espaciais (AEDE) é um conjunto de técnicas utilizadas para detecção de padrões de associação e distribuição espacial, identificação de localidades atípicas e visualização da ordenação espacial de determinada seleção de dados (Anselin, 1988; Almeida, 2012). Suas técnicas são constituídas por um conjunto de indicadores univariados e bivariados ou multivariados, que avaliam as posições absolutas e relativas dos dados nos âmbitos global e local, de modo a permitir a análise dos dados de diversas formas a partir de sua distribuição espacial. Para isso, os cálculos dos indicadores levam em consideração as localidades vizinhas definidas conforme uma matriz de pesos espaciais (ANSELIN, 1994).

As matrizes de pesos espaciais retratam o arranjo espacial das relações associadas às variáveis pesquisadas e sua correlação com as regiões vizinhas, capturando a intensidade das interações e as distâncias entre as regiões. Os elementos da matriz de pesos são não estocásticos e exógenos ao modelo. Considerando " $n$ " regiões, tem-se:

$$
W=\left[\begin{array}{ccc}
w_{11} & \cdots & w_{1 n} \\
\vdots & \cdots & \vdots \\
w_{n 1} & \cdots & w_{n n}
\end{array}\right]
$$

Onde $w_{i j}$ é a influência que a região $i$ exerce sobre a região $j$.

Para uma matriz de contiguidade de proximidade geográfica binária, atribui-se um valor a cada elemento da matriz: valor unitário, caso $i$ e $j$ sejam contíguos e valor nulo, caso não sejam. Convencionalmente, $w_{i i}=0$, pois uma região não pode ser vizinha de si mesma. A contiguidade pode ser determinada de acordo com a convenção torre, bispo ou rainha (Anselin et al., 1996; Almeida, 2012). 
Uma convenção de contiguidade é dita do tipo rainha se todos as regiões que possuem fronteira física com a região analisada são consideradas contíguas. Na convenção torre, são tidas como contíguas apenas as regiões em que extensão da fronteira física é superior a zero. Finalmente, na convenção do tipo bispo, são consideradas contíguas as regiões cuja fronteira é constituída apenas por um vértice entre a região principal e a região analisada (Almeida, 2012).

Para este estudo, foram testadas as matrizes de contiguidade do tipo torre, bispo e rainha, uma vez que não era necessário capturar nenhum outro tipo de dependência, além da puramente espacial. Optou-se pelo uso da matriz de contiguidade do tipo torre, por ter sido, dentre as testadas, a matriz que capturou de forma mais precisa, via I de Moran, a dependência espacial dos dados. Desta maneira, a matriz do tipo torre se mostrou a mais adequada às relações espaciais existentes na base de dados utilizada.

Para a mensuração da dependência espacial, recorre-se a técnicas univariadas ou bivariadas. A autocorrelação espacial univariada determina padrões espaciais associados à distribuição de uma única variável. Divide-se em indicadores globais e locais. Os primeiros testam se as variáveis espaciais apresentam dependência em relação aos seus vizinhos, ou seja: "o grau em que o conjunto dos dados está agrupado disperso ou distribuído aleatoriamente" (Almeida, 2012, p. 120). São eles: a estatística I de Moran, estatística c de Geary e estatística G de Getis-Ord, além da contagem de junções. Os coeficientes bivariados medem a correlação entre determinada variável em uma região e uma variável distinta nas regiões vizinhas.

O I de Moran univariado é o indicador mais utilizado dentre os acima mencionados, cuja função é demonstrar o grau de associação linear dos valores observados entre as regiões de determinada variável de interesse, ponderando as defasagens espaciais. Matricialmente, é dado por:

$$
I=\frac{n}{S_{0}} \frac{z^{\prime} W z}{z^{\prime} Z}
$$

Onde $z$ é o vetor de $n$ observações para o ano analisado, em formato de desvios padrões; $W$ é a matriz de pesos espaciais e $S_{0}$ é a soma dos elementos da matriz. O valor esperado para este índice é $\frac{-1}{n-1}$. Se o valor obtido for menor do que o valor esperado, há uma correlação espacial negativa, isto é: regiões com um grande (pequeno) efeito diferencial em determinada categoria de anos de estudo 
estão cercadas por regiões com um pequeno (grande) efeito diferencial nesta mesma categoria. O mesmo pode ser dito do efeito estrutural. Assim, há heterogeneidade espacial. Se o valor obtido for superior ao valor esperado, há uma correlação espacial positiva, onde regiões com um grande (pequeno) efeito diferencial para determinada categoria de anos de estudo estão cercadas por regiões onde há um grande (pequeno) efeito diferencial para esta mesma categoria. Novamente, a mesma análise pode ser feita para o efeito estrutural.

Entretanto, em alguns casos, os indicadores de autocorrelação espacial global podem ocultar ou camuflar padrões de associação locais, tornando necessário o uso de índices locais que forneçam uma visão mais específica da autocorrelação do efeito diferencial e do efeito estrutural de cada categoria de estudo em determinada região, uma vez que os indicadores globais revelam grupos de autocorrelação espacial estatisticamente significativos ou não (Almeida, 2012).

Estes indicadores são também denominados LISA (indicadores locais de associação espacial) e satisfazem a dois critérios: indicam apenas os clusters espaciais com significância estatística e, se somados para todas as regiões, são proporcionais a seu indicador global correspondente. São eles: I de Moran local, ci de Geary local e Gi local, entre outros, sendo o primeiro mais relevante (Anselin, 1994; Almeida, 2012)

O I de Moran Local univariado decompõe o índice global para cada observação $i$ nas categorias alto-alto, baixo-baixo, alto-baixo e baixo-alto, de forma correspondente aos quadrantes do diagrama de dispersão de Moran. Para uma variável (y) padronizada, observada na região $i, z i$, o I de Moran local é dado por:

$$
I_{i}=z_{i} \sum_{j=1}^{J} w_{i j} z_{j}
$$

\subsection{Método Estrutural-Diferencial (Shift-Share)}

O método shift-share consiste numa técnica para encontrar fatores internos e externos que explicam o crescimento de uma região. É feita uma comparação entre o crescimento do número real de pessoas em cada categoria de anos de estudo e do número teórico para cada região, onde o crescimento real se refere ao efetivamente observado e o crescimento teórico reflete o esperado, de acordo com 
a evolução de todas as regiões da área de referência, isto é, o Brasil. A diferença entre ambos revela o comportamento de dinamismo da região (Haddad, 1989).

O grau de dinamismo da região decorre de fatores estruturais, ou seja, referentes à composição industrial da região, e fatores diferenciais, que ocorrem em função da especialização em vantagens comparativas regionais. A quantidade de indivíduos em cada categoria de anos de estudo, em cada região, é decomposta, portanto, entre dois anos, onde um deles é tomado como ano-base. Assim, pode ser feita uma análise a respeito da parcela de variação associada a fatores internos ou externos (Haddad, 1989). A variação líquida total, portanto, é dada por:

$$
T_{i j}=E_{i j}^{0}\left(e_{i}-e\right)+E_{i j}^{0}\left(e_{i j}-e_{i}\right)
$$

Onde $T_{i j}$ é a variação líquida total, $E_{i j}^{0}\left(e_{i}-e\right)$ é a variação estrutural e $E_{i j}^{0}\left(e_{i j}-e_{i}\right)$ é a variação diferencial.

\section{Resultados e discussão}

A seguir, a tabela 1 apresenta o I de Moran univariado para cada um dos efeitos analisados nesta pesquisa, bem como para a variação líquida total, para cada categoria de escolaridade, além do total. Como pode ser observado na tabela, para todas as variáveis o I de Moran apresentou um valor positivo, indicando que regiões de alta (baixa) variação líquida total, variação estrutural ou variação diferencial estão cercadas de regiões de alta (baixa) variação líquida total, variação estrutural ou variação diferencial, respectivamente. Isto é: as microrregiões brasileiras tendem a formar polos de atratividade ou repulsão por nível de escolaridade.

Assim, é perceptível que há dependência espacial significativa. Para a grande maioria das variáveis, esta dependência é forte, pois o índice de Moran ultrapassa 0,5. Também é possível observar que o valor do I de Moran é decrescente da categoria 1 para a categoria 4, para os efeitos estrutural e diferencial e, por consequência, também para a variação líquida total. Isto é um indicativo de que a dependência espacial é mais forte para menores graus de escolaridade, excetuando-se a categoria 0 . Ou seja: indivíduos mais instruídos tendem a ter menor concentração espacial.

O efeito diferencial, que será mais explorado adiante, é o responsável por fornecer evidências de migração. Ao observar o I de Moran para esta variável, esta 
redução da concentração espacial para maiores níveis de instrução pode ser percebida como um indício da presença da fuga de cérebros no Brasil.

\section{Tabela 1 - I de Moran Univariado para a variação líquida total e para os efeitos diferencial e estrutural por nível de instrução}

\begin{tabular}{lc}
\hline \multicolumn{1}{c}{ Variável } & I de Moran Univariado \\
\hline Variação Líquida Total para a categoria 0 & 0,560646 \\
Variação Líquida Total para a categoria 1 & 0,613094 \\
Variação Líquida Total para a categoria 2 & 0,524577 \\
Variação Líquida Total para a categoria 3 & 0,438457 \\
Variação Líquida Total para a categoria 4 & 0,350813 \\
Variação Líquida Total para o total & 0,532743 \\
Efeito Estrutural para a categoria 0 & 0,78756 \\
Efeito Estrutural para a categoria 1 & 0,757379 \\
Efeito Estrutural para a categoria 2 & 0,680584 \\
Efeito Estrutural para a categoria 3 & 0,526196 \\
Efeito Estrutural para a categoria 4 & 0,587479 \\
Efeito Estrutural para o total & 0,46395 \\
Efeito Diferencial para a categoria 0 & 0,574453 \\
Efeito Diferencial para a categoria 1 & 0,674683 \\
Efeito Diferencial para a categoria 2 & 0,503299 \\
Efeito Diferencial para a categoria 3 & 0,358518 \\
Efeito Diferencial para a categoria 4 & 0,338597 \\
Efeito Diferencial para o total & 0,5235 \\
\hline
\end{tabular}

Fonte: Elaborado pelos autores com base nos dados do IBGE e no software GeoDa.

Além do I de Moran, foram elaborados os mapas de cluster a partir do I de Moran local para as microrregiões, para cada subdivisão do nível de instrução e para o total, a partir dos efeitos diferencial e estrutural, assim como para a variação líquida total. A seguir, são apresentados na figura 2 os mapas de cluster para a variação líquida total: 
Figura 2 - Mapas de cluster da variação líquida total para o nível de instrução por microrregião (2000-2010)
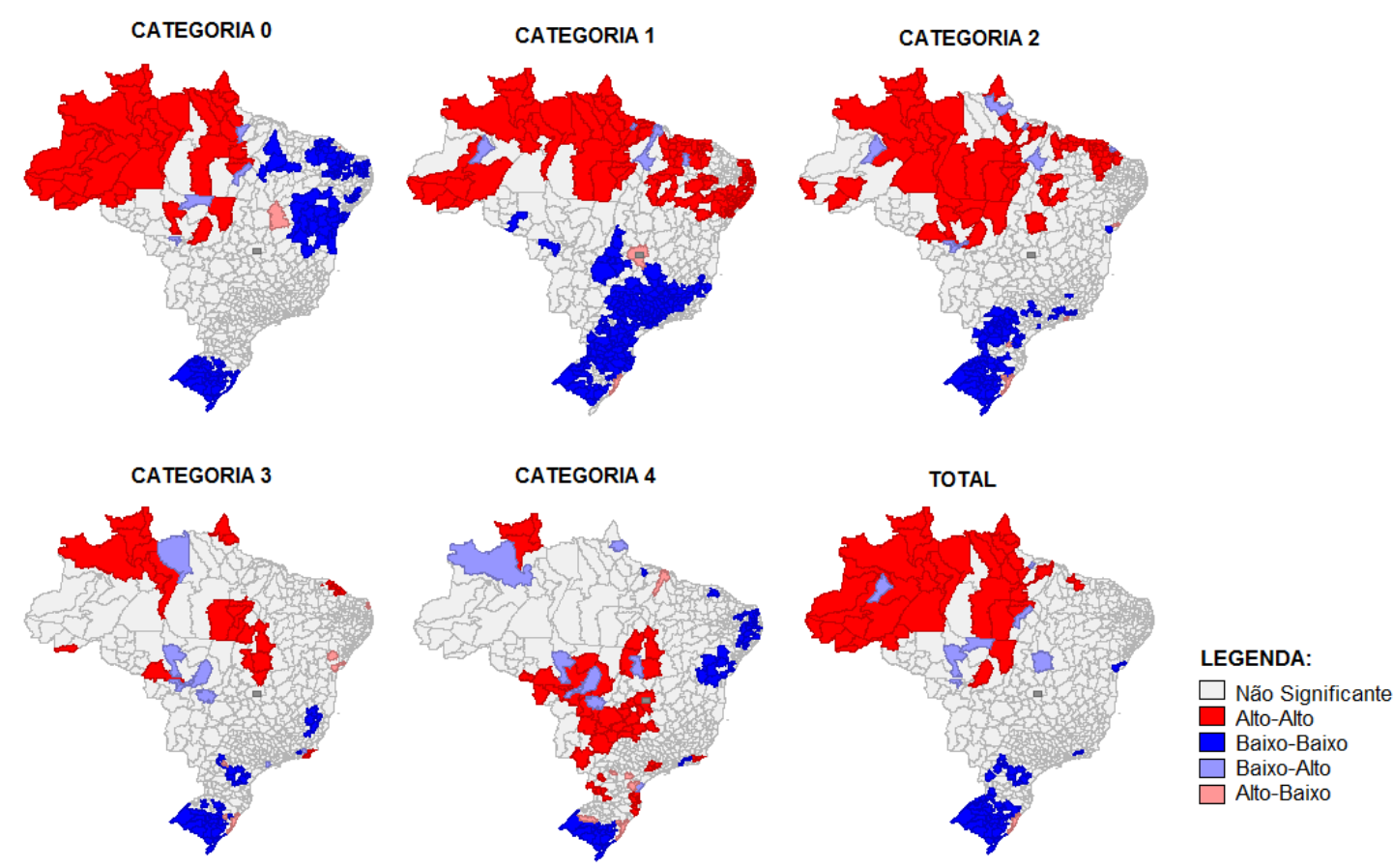

Fonte: Elaboração própria com base nos dados do IBGE e no software GeoDa.

A variação líquida total é dada pela diferença entre as variações real e teórica, e indica o montante da população que cada microrregião obteve entre 2000 e 2010. É possível observar, na figura 2, que os clusters do tipo alto-alto estão predominantemente agrupados nas regiões Norte e Nordeste do país para níveis de instrução baixos ou médios e, para níveis de instrução mais altos, estão presentes de maneira mais significativa na região central brasileira, bem como na região Norte. Já os clusters do tipo baixo-baixo encontram-se concentrados na região Sul do país, estando também presentes no Nordeste e Sudeste.

Desta maneira, as regiões Nordeste e principalmente Norte têm ganhado população com menores níveis de instrução, uma vez que ao aumentar o grau de escolaridade, o cluster diminui. Enquanto isso, conforme é aumentado o grau de instrução observado, os clusters do tipo baixo-baixo diminuem. Assim, para graus de instrução menores, a população se reduz no Sul e no Sudeste do país e cresce predominantemente na região Norte, enquanto para uma escolaridade mais alta, a população diminui na região Sul e cresce nas regiões Norte e Centro-Oeste. 


\section{Figura 3 - Mapas do efeito estrutural para o nível de instrução por microrregião (2000-2010)}
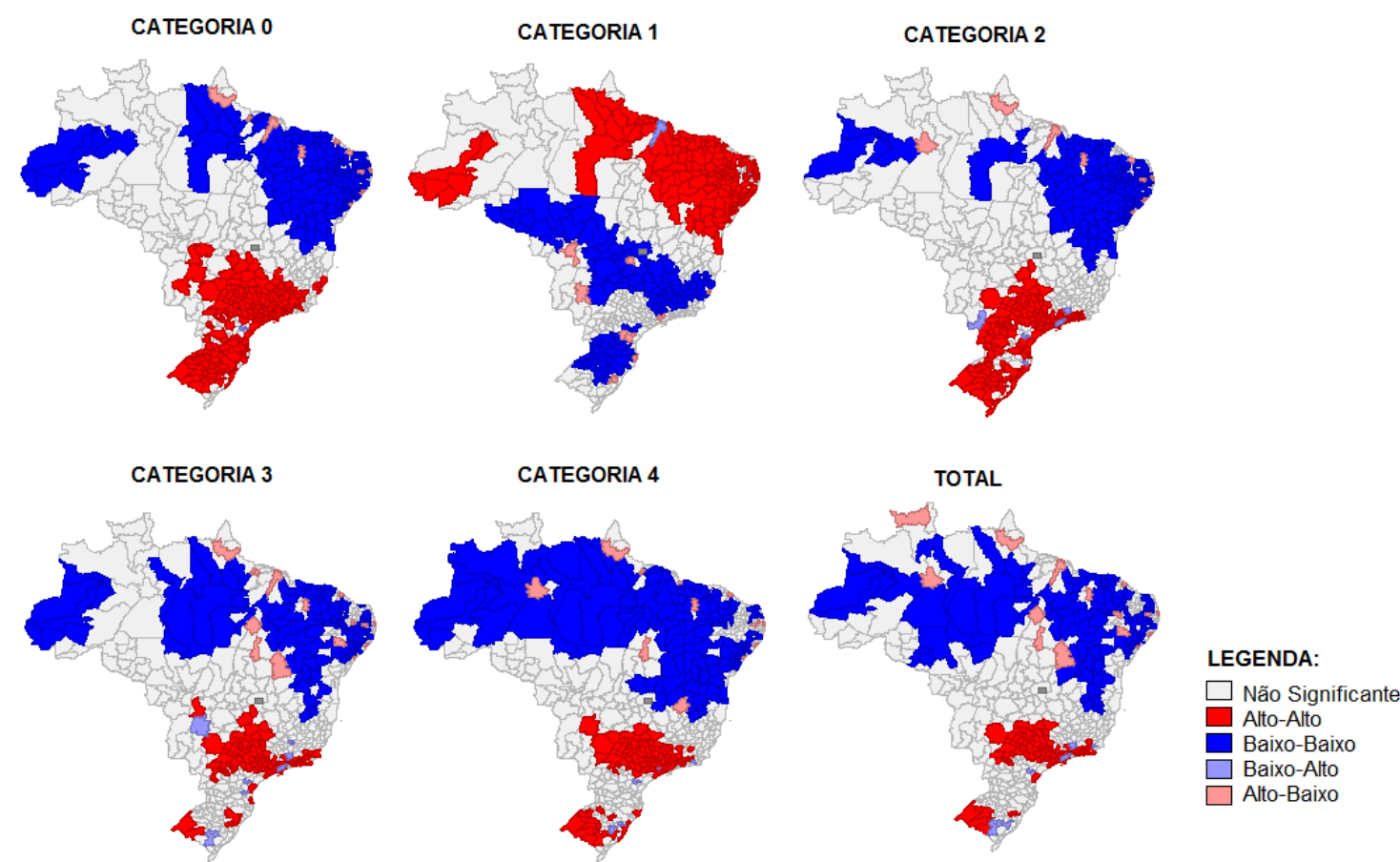

Fonte: Elaboração própria com base nos dados do IBGE e no software GeoDa.

O efeito estrutural indica a presença de dinamismo nas microrregiões, em função de sua composição por grau de escolaridade. Como pode ser observado na figura 3, valores negativos ocorreram para as categorias 0 e 1 indicando que, no geral, a participação destas na população total se reduziu. Para as categorias 2, 3 e 4, o efeito estrutural foi positivo, mostrando que a participação destas categorias no total da população brasileira aumentou. Para este efeito, é possível notar, na figura 7, a presença de clusters do tipo alto-alto nas regiões Sul e Sudeste para todas as categorias, com exceção da categoria 1, na qual os clusters do tipo altoalto concentram-se no Norte e Nordeste. Os clusters do tipo baixo-baixo, por sua vez, apresentam-se no padrão oposto: estão significativamente agrupados nas regiões Norte e Nordeste do país para quase todas as categorias de grau de instrução, exceto pela categoria 1, que concentra os clusters baixo-baixo nas regiões Sul, Sudeste e Centro-Oeste.

Para a categoria 0 , os clusters observados podem ter explicações puramente demográficas. Quanto à categoria 1, o posicionamento de seus clusters de forma oposta à das demais categorias pode ser explicado por deslocamentos de empresas 
que demandam mão de obra com baixa qualificação para fora de regiões metropolitanas e grandes centros urbanos, em busca de mão de obra mais barata. Desta maneira, a ocupação territorial, o desenvolvimento urbano e o aumento da demanda por capital humano com pouca qualificação podem ser causa da presença de um decréscimo da participação de indivíduos da categoria $1 \mathrm{com}$ taxas mais baixas nas regiões Norte e Nordeste em relação às taxas de decréscimo da presença desta categoria nas demais regiões do país.

\section{Figura 4 - Mapas do efeito diferencial para o nível de instrução por microrregião (2000-2010)}
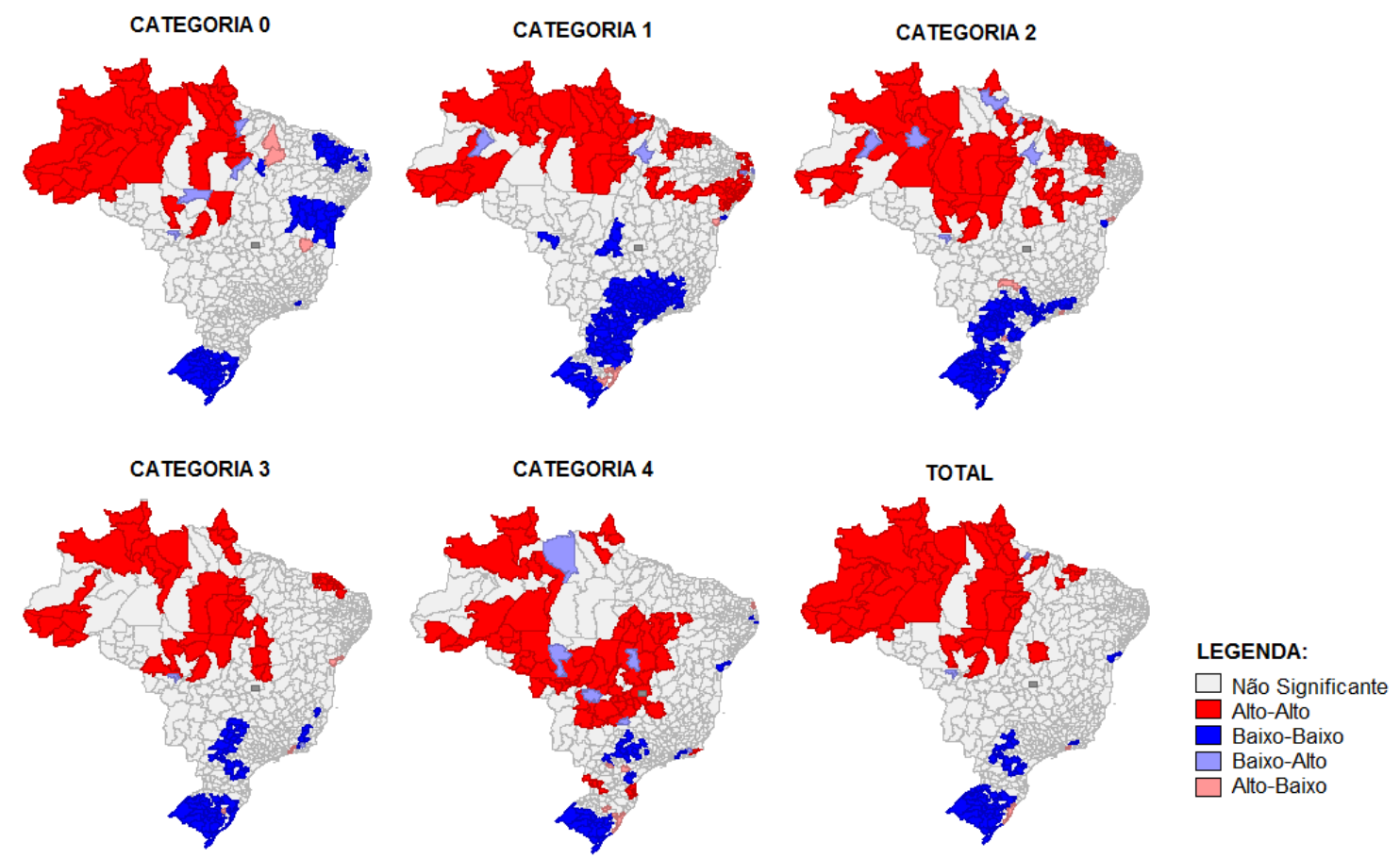

Fonte: Elaboração própria com base nos dados do IBGE e no software GeoDa.

Para as categorias que obtiveram um valor positivo para o efeito estrutural, os clusters podem ser explicados pela base econômica das microrregiões: locais em que há estruturalmente uma parte maior da população com mais escolaridade, em comparação com outros locais - isto é, os clusters do tipo alto-alto - tendem a aumentar a presença destes em sua composição, enquanto nas regiões com baixa participação - ou seja, os clusters do tipo baixo-baixo - ocorre o contrário.

Por fim, o efeito diferencial indica o montante populacional que cada microrregião obteve devido à diferença de sua taxa de crescimento populacional 
em relação à média nacional, capturando os efeitos de atratividade ou repulsão de cada localidade. Para todas as categorias, bem como para o total, é notável na figura 4 uma significativa presença de clusters do tipo alto-alto nas regiões Norte, Nordeste e parte da região central do Brasil. Comparando com os clusters formados pela variação líquida total, é perceptível que o efeito diferencial tem um peso maior no efeito total, comparado ao efeito estrutural.

Conforme o aumento do grau de instrução, é possível observar um espraiamento dos clusters alto-alto, indicando que para uma maior escolaridade, a região central do país apresenta mais atrativos, podendo ser um indicativo de desenvolvimento da região. Para menores graus de instrução, os clusters do tipo alto-alto concentram-se principalmente na região Norte, estando também presentes na região Nordeste. Isso indica que essas regiões têm sido atrativas para indivíduos com baixa escolaridade, e consequentemente, na média, menores salários, potencialmente agravando a má situação da distribuição de renda no Brasil, uma vez que essas regiões historicamente apresentam menores níveis de renda em comparação com as demais regiões brasileiras.

Os clusters baixo-baixo estão presentes majoritariamente na região Sul, mais notavelmente no Rio Grande do Sul. Assim, este estado tem perdido população de todos os níveis de instrução. Quanto à categoria zero, o Nordeste apresenta redução demográfica. Para as demais categorias, este fenômeno também ocorre no Sudeste.

Tanto os clusters baixo-baixo quanto os alto-alto podem ser indícios de movimentos migratórios em busca de melhores salários, conforme apontado pela teoria econômica. Regiões com menores atrativos para indivíduos de certa categoria de escolaridade podem estar perdendo população desta mesma categoria. Entretanto, as categorias com maiores graus de instrução apresentam destaque para essa possibilidade, uma vez que para baixos níveis de escolaridade, o salário costuma ser menor, dificultando a ocorrência de movimentos migratórios.

\section{Considerações finais}

Esta pesquisa buscou realizar uma análise espacial para os dados populacionais por categoria de grau de instrução no Brasil, para os anos de 2000 e 2010, através da metodologia shift-share. Pôde ser observada uma dependência espacial significativa para todas as categorias de escolaridade, para os efeitos 
diferencial e estrutural, bem como para a variação líquida total, majoritariamente forte. Além disso, conforme aumenta o grau de instrução, a dependência espacial perde força, evidenciando que o processo de "fuga de cérebros" tem sido espacialmente mais disperso no Brasil.

Em uma análise local, a variação líquida total apresentou clusters do tipo alto-alto nas regiões Norte e Nordeste do país para níveis de instrução menores, enquanto para níveis de instrução mais altos, estes estão significativamente presentes no Centro-Oeste e no Norte do Brasil. Assim, conclui-se que notavelmente a região Norte tem ganhado população com menos escolaridade, enquanto a região central do país se destaca pelo aumento da presença de indivíduos com maior grau de instrução. Esse resultado indica que a base econômica do centro-oeste tem atraído mão de obra mais qualificada, contribuindo para seu processo de desenvolvimento. Já no caso do Norte e Nordeste isso não parece ocorrer, de modo que se reforça as dificuldades enfrentadas por essas regiões quanto à disparidade regional com o Sul, Sudeste e, agora, Centro-Oeste.

Quanto à composição estrutural, foram encontrados valores negativos para as categorias 0 e 1 e positivos para as categorias 2,3 e 4, o que indica que, em geral, a participação de categorias de menor grau de instrução na população brasileira diminuiu, enquanto a participação de categorias com maior escolaridade aumentou no período observado. O maior aumento ocorreu na categoria 3, que inclui indivíduos com o ensino médio completo ou ensino superior incompleto. Vale ressaltar que o componente estrutural capta os efeitos de mudança na composição agregada da população segundo o nível de escolaridade. Assim, esses resultados são consistentes com a tendência geral de mudança nos grupos populacionais por nível de escolaridade.

Para praticamente todas as categorias, formaram-se clusters alto-alto nas regiões Sul e Sudeste, bem com clusters do tipo baixo-baixo nas regiões Norte e Nordeste, condizendo com a estrutura brasileira em termos de escolaridade. No entanto, a categoria 1 apresentou um padrão oposto de aglomerações na região Nordeste, que possivelmente se deve ao crescimento de atividades produtivas que demandam mão de obra de menor qualificação das aglomerações urbanas desta região.

Por fim, quanto ao efeito diferencial, para todas as categorias e para o total, é notável uma significativa presença de clusters do tipo alto-alto nas regiões Norte, 
Nordeste e parte da região central do Brasil, indicando que o efeito diferencial tem um peso maior no efeito total, comparado ao efeito estrutural. $\mathrm{O}$ cluster do tipo alto-alto para a categoria 4, a de maior escolaridade, é mais concentrado na região central do Brasil. Esse padrão demonstra certa dominância de indivíduos com baixo grau de instrução em regiões de menor renda e reforça os indícios de desenvolvimento da região Centro-Oeste devido ao aumento da presença de indivíduos com maior escolaridade nesta região.

Os resultados dos clusters para o componente diferencial podem ser associados a dinâmica de migração da população segundo o nível de escolaridade. Assim, há evidências de movimentos migratórios no Brasil de acordo com a escolaridade. A já mencionada fuga de cérebros pode ser caracterizada pelos clusters do tipo baixo-baixo para os níveis de instrução mais altos e se mostra mais concentrada no Rio Grande do Sul. Os movimentos migratórios no período analisado, para os indivíduos mais escolarizados provenientes de outros locais do país, parecem ocorrer em direção à região Centro-Oeste. A agenda de pesquisa pode então avançar para estudar em mais profundidade os fatores de influenciam os fluxos de migração dos diferentes grupos populacionais segundo o nível de escolaridade, bem como os impactos econômicos dos resultados observados nesta pesquisa.

\section{Referências}

ANSELIN, L.; BERA, A.; FLORAX, R.; YOON, M. Simple diagnostics tests for spatial dependence. Regional Science and Urban Economics, v. 26, n. 1, p. 77104, 1996.

ANSELIN, L. Exploratory spatial data analysis and geographic information systems. In: PAINHO, M. (Ed.) New tools for spatial analysis: proceedings of the workshop. Luxemburgo: EuroStat, 1994.

ANSELIN, L. Spatial Econometrics: Methods and Models. Dordrecht: Kluwer Academic Publishers, 1988.

ALMEIDA, E. Econometria espacial aplicada. Campinas: Editora Alínea, 2012.

BECKER, G. Nobel lecture: the economic way of looking at behavior. Journal of political economy, v. 101, n. 3, p. 385-409, 1993.

BODVARSSON, Ö.; VAN DEN BERG, H. The economics of immigration. New York: Springer, 2013. 
BORJAS, G. Immigration and self-selection. In: ABOWD, J.; FREEMAN, R. (Eds.). Immigration, trade, and the labor market. Chicago: University of Chicago Press, 1991.

BORJAS, G. The economic benefits from immigration. Journal of economic perspectives, v. 9, n. 2, p. 3-22, 1995.

BRZOZOWSKI, J. Migração internacional e desenvolvimento econômico. Estudos avançados, v. 26, n. 75, p. 137-156, 2012.

CAMPINO, A. A migração de pessoas qualificadas no período 1950/70. Pesquisa e Planejamento Econômico, v. 3, n. 4, p 1091-1102, 1973.

FERREIRA, R; MATOS, R. Migração de trabalhadores no mercado formal brasileiro entre 1995 e 2003 e as tendências da reestruturação territorial. In: XIV Encontro Nacional de Estudos Populacionais, 2006.

FREGUGLIA, R.; PROCÓPIO, T. Efeitos da mudança de emprego e da migração interestadual sobre os salários no Brasil formal: evidências a partir de dados em painel. Pesquisa e Planejamento Econômico, v. 43, n. 2, p. 255-278, 2013.

FURTADO, C. Formação econômica do Brasil. São Paulo: Companhia das Letras, 1959 (2007).

GOLGHER, A. Fundamentos da migração. Texto para Discussão n. 231. Belo Horizonte, Cedeplar/UFMG, 2004.

GOLGHER, A. Diagnóstico do processo migratório no Brasil 1: comparação entre não migrantes e migrantes. Texto para Discussão n. 282. Belo Horizonte, Cedeplar/UFMG, 2006.

HADDAD, P. Método de análise diferencial estrutural IN: HADDAD, P. (Org.). Economia regional: teorias e métodos de análise. Fortaleza: Banco do Nordeste do Brasil, 1989.

HAKKERT, R.; MARTINE, G. Tendências migratórias recentes no Brasil: as evidências da PNAD de 2004. Parcerias Estratégicas, v. 11, n. 22, p. 347-379, 2010 .

OLIVEIRA, A.; SIMOES, A. Deslocamentos populacionais no Brasil: uma análise dos Censos Demográficos de 1991 e 2000. Cadernos de Estudos Sociais, v. 20, n. 1, p. 1-20, 2004. 
RAMALHO, H.; QUEIROZ, V. Migração interestadual de retorno e autosseleção: evidências para o Brasil. Pesquisa e Planejamento Econômico, v. 41, n. 3, p. 369396, 2011.

RIGOTTI, J. Geografia dos fluxos populacionais segundo níveis de escolaridade dos migrantes. Estudos avançados, v. 20, n. 57, p. 237-254, 2006.

SABBADINI, R.; AZZONI, C. Migração interestadual de pessoal altamente educado: evidências sobre a fuga de cérebros. In: Encontro Nacional de Economia, v. 34, 2006.

SJAASTAD, L. The costs and returns of human migration. Journal of Political Economy, v. 70, n. 5, p. 80-93, 1962. 